\title{
Post-Humanitarianism: The Lifestyle Solidarity of the 21st Century
}

\author{
Lilie Chouliaraki (London School of Economics and Political Science)
}

\begin{abstract}
:
Liking the Instagram post of a humanitarian celebrity, e-shopping from a charity shop or signing an online petition on Black Lives Matter have become popular forms of digital activism. While such activism, what I call post-humanitarian solidarity, has helped popularize important causes worldwide, in this paper, I argue for the need of a critical pedagogy that also alerts us to the limitations of this form of activism. It is, in particular, the synergy of corporate humanitarianism with the entertainment industry and platform capitalism that such critical pedagogy should focus on, raising questions about the political and ethical implications of post-humanitarian solidarity and the kinds of global publics it gives rise to.
\end{abstract}

Keywords:

digital activism; marketization; platform capitalism; post-humanitarian solidarity

\section{Post-Humanitarianism: A Definition}

We often think of solidarity as a spontaneous feeling that springs from the heart, when we see people suffer or we feel an injustice has been done. Solidarity, however, is not a natural human emotion. It is a public disposition that is nurtured by our culture and institutions, including largely educational institutions. It is shaped by its own time and place. And it requires active work in order to emerge and to continue to thrive.

The solidarity of the $21^{\text {st }}$ century is itself the product of our historical moment. And as I argue in 'The Ironic Spectator' (Chouliaraki, 2013), it is inherently related to the particular 'spirit' of our era, the neoliberal spirit of branddriven consumption and platform activism, which infuses the dominant narratives, spectacles and imaginations of public life across western cultures - though inevitably there are variations. In the book, I show that, as a result of this neoliberal spirit, contemporary solidarity - what I also call "post-humanitarianism" - is a market-oriented solidarity that remains sceptical of all ideological visions of a better society and is content with the management of the present, the pursuit of personal interest and minor gratifications of the self. This is a what's-in-it-for-me ethics, informed by a sense of individualist entitlement and a utilitarian pragmatism of the everyday. A recent example is the March 2020 Instagrambased celebrity-driven campaign for compassion and resilience in the face of suffering during the pandemic, which figured a range of celebrities, each signing a verse of John Lennon's "Imagine" to spread a message of universal togetherness while accumulating likes and consolidating personal brands (Caramanica, 2020). This particular campaign backfired badly with fans criticizing its narcissistic aesthetics and so, in its failure, it highlighted just how much the communication of solidarity today takes place on social media platforms used by privileged individuals, NGO brands or corporate industries (from fashion to football) as a winwin of doing good and building reputations.

Placing such campaigns under scrutiny is a vital pedagogic undertaking insofar as younger generations' engagement with social issues takes place primarily online and so such forms of solidarity are both widespread and popular among the young (Bennett, 2014). Relativizing its content, actors, and practices by situating posthumanitarianism in a broader chronological trajectory of humanitarian communication is one way of introducing a critical awareness of this kind of solidarity in the education process. The comparison of the post-humanitarian moment (exemplified by the celebrity advocacy of Angelina Jolie) with past forms of solidarity in the 60s and 70s (illustrated by Bob Dylan, Peter Gabriel), for example, is useful in helping us better understand how this form of solidarity differs from the past. There are two key differences between the two that I would like to draw attention to. The first difference has to do with the broader message that celebrity advocacy carries to its publics and the second is about the relationship between celebrity advocacy and civil society. Singer and Nobel laureate Bob Dylan and rock star Peter Gabriel were activists of their time in that they both participated in and articulated the concerns and demands of the peace (1960s) or anti- 
apartheid (1970s and 1980s) movements respectively. They were, in other words, part of a broader critical narrative of political critique that spoke against power and injustice and fought for social change.

Today, Angelina Jolie's message is part of a huge mutual branding campaign run by the UN. She offers her worldfamous name and face as massive symbolic capital in order to boost UN's reach and popularity around the globe while the UN offers Jolie 'moral' capital, allowing her to enhance her brand name not only as a Hollywood star but also as a virtuous humanitarian persona. They two are locked in a winwin pact. Both gain legitimacy, in the process, whether institutional (UN) or personal (Jolie). This may not minimize Jolie's contribution to her causes; it does, however, situate her advocacy in a different political economy to that of her predecessors, where, rather than speaking for or on behalf of civil society, she speaks for a major organisation in the global governance market; and, consequently, it further consolidates a different political culture - one that, rather than collectivist, is fully individualised within a platform-driven social space. Indeed, the UN's communication strategy centers upon social media metrics ("follows", "likes" and "shares") as evidence of its campaigns' popularity and reach rather than centering on cultivating a more participatory and activist engagement with the causes that it promotes. Importantly, nor is the UN interested in formulating a more radical plan for social change in the power relations between West and global South. And how could it, given that the UN itself, including the celebrities supporting it, are an integral part of the dominant governance system that perpetuates these relations of power.

This historical example of comparative pedagogy is not meant, as mentioned, to minimise the difference that celebrity advocacy, by Jolie and others, has made in major emergencies by drawing vital attention and money to them, whether it is Syrian war camps or the Mediterranean refugee crisis. It does, however, draw attention to the status of celebrity-driven activism as part of a new instrumental culture of solidarity that remains content with the operational management of global crises and promotes fleeting forms of twitter compassion without the vision of social change - of a just redistribution of global resources between West and global South.

\section{Historical Reasons for Post-Humanitarianism}

However, to stick to the post-humanitarian claim as the only possible diagnosis of solidarity today could be a pedagogically reductive and socially pessimistic conclusion. Continuing with the importance of historicizing solidarity as a pedagogic strategy, a key aim for us as teachers and educators is to try to better understand and communicate to younger generations how we got here and what could make alternatives possible. I argue that there are at least three key historical forces that have contributed to the formation of post-humanitarian solidarity.

The first is the retreat of the major ideologies of the $20^{\text {th }}$ century, that is the demise of the great social visions that guided the generations of the $20^{\text {th }}$ century. The first such vision, what we may call, salvation includes religious faith, in the form of Christian altruism (agape), with its own forms of charity either within the church or through other philanthropic agencies; and humanitarian assistance, in the secular project of alleviating the pain of the sufferer, for example in Eric Dunant's Red Cross that treats the war wounded on both sides of a conflict as well as an increasing number of non-governmental organisations that offer first aid in emergencies around the world. The second vision, what we may call revolution, speaks to the project of social change in the name of a free society (Marxian class struggle or postcolonial movements) or, in the post-World War Two order, to the project of a peaceful and equitable international order in the name of human rights. With the exception of the latter, human rights, which has today become the dominant language of the international order (Moyn 2010), most grand visions of the $20^{\text {th }}$ century have not survived the post-Cold War world order intact, and, following the fall of the Berlin Wall in 1989, new geo-political and ideological arrangements replaced old certainties with a culture of fragmentation, competing values and epistemic doubt.

The second reason is the marketisation of key professional sectors that articulate the moral messages of solidarity. Since the early 1990s, an economic boom within the humanitarian sector meant that NGOs are today competing for money, attention and prestige within a global market of state and private donors and are consequently turning more towards corporate strategies for communication and funding rather than focusing on the contexts they are meant to assist. In a parallel move, International Development agencies focus on the micro-financial management of poverty rather than on macro-economic issues, such as fairer market regulations and distribution of resources. It is within this political economy of neoliberal competition that the sector had to 'professionalise' its messages by outsourcing advertising campaigns, turning to celebrity branding and, overall, privileging utilitarian pragmatism over a pedagogy of justice.

The third reason is the digitization of culture, that is the rise of digital media with their profit-oriented and extractive platforms (Instagram, Facebook etc) and their self-referential forms of communication. Even though social media have obvious advantages, such as instant and horizontal connectivity, they are also driven by algorithms that amplify pre-existing preferences (recommending what users already like) and that ultimately give voice to those who are already voiced (the more access you have and the more active you are, the more visibility you get). Such platforms create, therefore, echo chambers where those with access to digital 
platforms (financial, social) tend to congregate around similar voices while excluding others and ignoring those outside the digital bubble. As a result of this hierarchy of participation, social media tend to reproduce the divisions and exclusions that exist outside the digital sphere and to deprive vulnerable others, proximal and distant, of their own voice.

While there is no straightforward causal link among these three historical forces, taken together, they came to construe a new political and cultural context, where ideological belief and street activism became gradually replaced by depoliticised, consumption-oriented and networked-driven forms of activism that updated old messages in the language of branding and yielded profits to their organisations.

\section{The Pedagogical Critique of Post-Humanitarian Solidarity}

What this historical overview does is that it adds an explanatory element in the pedagogy of solidarity. As these three historical trends converge in the current moment, educational discourse can now not only position the practice of post-humanitarian solidarity within its specific context but also raise the question of what kind of citizens we become by practising it. As a form of activism that uses easy, ad-like messages in order to motivate us to donate, sign a petition or buy a commercial product to benefit a cause, posthumanitarianism is fully tailored to sell a cause to the busy, multi-tasking, media-savvy and relatively wealthy western citizen/consumers that can potentially do good but lack the time or energy to engage extensively with solidarity activism.

Essentially such organisations use their messages to sell their brand as a 'product' that has little to do with politics, but which has the operational capacity to intervene efficiently in complex political contexts in order to produce 'results'. Critical pedagogy must understand and address this trend towards the de-policitisation of solidarity in order to resist it. Instead of continuing to sustain the post-humanitarian myth that political questions of humanitarian crises or human rights violations can be addressed through consumer activism, the question we need to introduce in educational discourse is how we could best acknowledge and account for the relationship between solidarity and politics. And instead of accepting uncritically the market and its corporate strategies as ways to increase or solidify the reputation of NGOs, we should be initiating an open debate within schools and universities about what it means, morally and politically, for such organisations to claim legitimacy and what it would take for them to become forces of systemic change in the communities they work in/with. Such debates would raise the difficult but necessary questions of causality (how can we transform the conditions of people's suffering?), justice (what is the right thing to do and how to do it?) and otherness (who are the beneficiaries? where are their voices?). In so doing, such pedagogy of solidary would also address students as citizens of the world who are keen to understand and change the world they live in rather than being simply consumers or twitter users.

These questions are an important part of any educational curriculum precisely because the cost of the lifestyle solidarity, currently so central in youth culture, is that it does nothing to cultivate an interest in the world beyond our own. It is too self-centred to push us outside our comfort zone by confronting us with those in need or/and by explaining why it is important to act on the predicaments of those others. Indeed, while it is financially successful for NGOs, such messaging simultaneously has measurably negative effects on public engagement. As research has shown, the actual knowledge and activism of consumerist publics with international causes has fallen in the first decade of the $21^{\text {st }}$ century (Henson \& Lindstrom, 2013); and, at the same time, there is a big gap between the publics' expectations of the communication of suffering and what NGOs believe they should be communicating - with the former wishing a longer-term and relational connection to their beneficiaries and the latter insisting on one-off instant messages or emergency appeals (Orgad \& Seu, 2017). These are high political and cultural stakes that lie at the heart of a critical pedagogy of solidarity. Even though we should not reduce the question of solidarity to its communicative dimension, at the same time, we cannot deny that how a cause is communicated (worded, narrated, pictured) is decisive to our understanding not only of what solidarity is but of what citizenship is and how it should best be enacted. As such, the critical understanding of post-humanitarianism should be a central dimension of the educational process.

\section{Challenging Post-Humanitarianism: Towards a Critical Pedagogy of Solidarity}

As part of an educational programme, the task of challenging post-humanitarianism has two starting points (though it is by no means exhausted to these): a critical understanding of the social media platforms on which post-humanitarian solidarity circulates; and a heightened reflexivity with regards to humanitarian communication as a struggle over representation rather than as a final message that is here to stay.

With regards to the first, that is the political economy of social media, the starting question is how we could use digital platforms, such as Twitter or Instagram, in ways that foster rather than break down bonds of solidarity with vulnerable others? Could we use them to give voice to and listen carefully to others? Can we imagine other ways of relating and conversing with them? The pedagogic task here is, on the one hand, to acknowledge the significance of such platforms in galvanizing social movements such as BLM and \#MeToo, but also to point to their limitations in sustaining such movements online-only and in including only the digitallyprivileged and not others. On the other hand, the task is to 
critique the current business model of social media and to explore alternatives of how to leverage these platforms' capacity to feed into new circuits of connectivity and solidarity without compromising those people's privacy, safety and, broadly, their data rights. This business model uses algorithmic regulation that multiplies celebrity-driven, popular posts to draw users in an economy of attention that monetizes content while minimizing the visibility of nonpopular solidarity posts and thus our engagement with them.

Secondly, how stories are presented, who speaks and what is being said are not just chunks of information disseminated by technology but human-made, social constructions that can be criticised and changed. The struggle to give voice, psychological depth and historicity to suffering others. All those involved in representing vulnerable others need to maintain an active and reflexive effort to create images, stories and interactive encounters through which these others appear i) as human actors, with emotions, desires and opinions (rather than powerless victims or potential threats) and ii) as possessing personal biographies and collective histories (rather than being portrayed as ahistorical beings caught in the eternal present of their suffering); yet at the same time, iii) as caught in circumstances that are not of their own making yet impact them in harmful ways.

What these two dimensions of reflexive criticism suggest is that, rather than thinking of solidarity as being fully highjacked by a market-driven social media logic, it's better to think of it as a site of struggle, where dominant neoliberal, utilitarian and self-centred dispositions are today provisionally fixed but that can and do, in time and with effort, change. They also point to alternatives. Are posthumanitarian the only social media representations of solidarity? Returning to a previous example, BLM offers a clear pedagogic example of how solidarity in resistance to racism can start from concrete particulars around specific social issues that mobilize people on the ground as much as online. Beyond marketized forms of solidarity, in other words, there are also major grassroot initiatives that seek to make a real difference in the lives of those in need wherever they happened to emerge. Other examples here include the international wave of volunteers and activists in the Greek islands and Italian coasts during the massive migration flows of 2015 that continue to offer their support to asylum seekers encamped in the edges of Europe or the volunteer movement that developed during the pandemic in underprivileged neighbourhoods of UK and elsewhere to support the most vulnerable. As part of a pedagogy of solidarity, what these references do is that they act as important reminders that solidarity can leverage social media but also, importantly, can and must exist outside their platformized networks of connective activism. That solidarity can, in fact, rely on the realisation that the world is unfair, that human suffering needs to be addressed wherever it is with our embodied actions and collective congregations and that even minor actions of a committed community on the ground can and does make a difference.

\section{References}

Bennett L. (2014). 'If we stick together we can do anything': Lady Gaga fandom, philanthropy and activism through social media. Celebrity Studies, 15(1-2), 138-152. https://doi.org/10.1080/19392397.2013.813778

Caramanica, J. (2020, March 20). This 'Imagine' cover is no heaven. The New York Times. https://www.nytimes.com/2020/03/20/arts/music/coronavirus-gal-gadot-imagine.html

Chouliaraki L. (2013). The ironic spectator. Solidarity in the age of post-humanitarianism. Polity.

Henson, S., \& Lindstrom, J. (2013). “A mile wide and an inch deep”? Understanding public support for aid: The case of the United Kingdom. World Development, 42, 67-75. https://doi.org/10.1016/j.worlddev.2012.07.004

Orgad, S., \& Seu, B. (Eds.). (2017). Caring on crisis? Humanitarianism, the public and NGOs. Palgrave.

\section{Recommended Citation}

Chouliaraki, L. (2021). Post-humanitarianism: the lifestyle solidarity of the 21st century. On Education. Journal for Research and Debate, 4(10). https://doi.org/10.17899/on_ed.2021.10.2

\section{About the Author}

Lilie Chouliaraki is Professor of Media and Communications at the London School of Economics and Political Science. Her work focuses on the ethical and political complexities of communicating human suffering in the media and her publications on the topic include 'The Spectatorship of Suffering' (Sage, 2006), 'The Soft Power of War' (Benjamins, ed., 2008), 'The Ironic 
Spectator. Solidarity in the Age of Post-humanitarianism' (Polity, 2013), 'The Routledge Handbook of Humanitarian Communication' (co-ed with Anne Vestergaard, Routledge, in press) and 'The Digital Border. Mobility, technology and power in the age of social media' (with Myria Georgiou, New York University Press, 2021). 